Published in final edited form as:

Lancet Diabetes Endocrinol. 2018 August ; 6(8): 647-658. doi:10.1016/S2213-8587(18)30026-3.

\title{
The physiology of endocrine systems with ageing
}

\author{
Annewieke W van den Beld, PhD, \\ Department of Internal Medicine, Division of Endocrinology, Erasmus Medical Centre, Rotterdam, \\ Netherlands; Department of Internal Medicine, Groene Hart Hospital, Gouda, Netherlands
}

Prof Jean-Marc Kaufman, PhD,

Unit for Osteoporosis and Metabolic Bone Diseases, Department of Endocrinology, Ghent University Hospital, Ghent, Belgium

M Carola Zillikens, PhD, Department of Internal Medicine, Division of Endocrinology, Erasmus Medical Centre, Rotterdam, Netherlands

\section{Prof Steven WJ Lamberts, PhD,}

Department of Internal Medicine, Division of Endocrinology, Erasmus Medical Centre, Rotterdam, Netherlands

Josephine M Egan, MD, and

Laboratory of Clinical Investigation, National Institute on Aging, Baltimore, MD, USA

\section{Prof Aart J van der Lely, PhD}

Department of Internal Medicine, Division of Endocrinology, Erasmus Medical Centre, Rotterdam, Netherlands

\section{Abstract}

During ageing, the secretory patterns of the hormones produced by the hypothalamic-pituitary axis change, as does the sensitivity of the axis to negative feedback by end hormones.

Additionally, glucose homoeostasis tends towards disequilibrium with increasing age. Along with these endocrine alterations, a loss of bone and muscle mass and strength occurs, coupled with an increase in fat mass. In addition, ageing-induced effects are difficult to disentangle from the influence of other factors that are common in older people, such as chronic diseases, inflammation, and low nutritional status, all of which can also affect endocrine systems. Traditionally, the decrease in hormone activity during the ageing process has been considered to be detrimental because of the related decline in bodily functions. The concept of hormone replacement therapy was suggested as a therapeutic intervention to stop or reverse this decline. However, clearly some of these changes are a beneficial adaptation to ageing, whereas hormonal

Correspondence to: Dr Annewieke W van den Beld, Erasmus University Medical Centre, PO Box 2040, Rotterdam 3000 CA, Netherlands, a.vandenbeld@erasmusmc.nl.

Contributors

AWvdB contributed to the abstract, introduction, sections on the thyroid axis and the adrenal axis, and conclusion. J-MK contributed to the gonadal axis section. MCZ contributed to the section on bone and calcium homoeostasis. SWJL contributed to the abstract, introduction, and conclusion, and revised the manuscript. JME contributed to the section on glucose homoeostasis. AJvdL contributed to the section on the somatotropic axis.

Declaration of interests

We declare no competing interests. 
intervention often causes important adverse effects. In this paper, we discuss the effects of age on the different hypothalamic-pituitary-hormonal organ axes, as well as age-related changes in calcium and bone metabolism and glucose homoeostasis.

\section{Introduction}

Throughout adult life, all physiological functions begin to gradually decline. Ageing is characterised by changes in virtually all biological systems. Major changes to the endocrine system, as described in this Series paper, result in healthy ageing individuals with well recognised phenotypes. However, other factors, such as inflammation and calorie intake, also affect the ageing process, and are often associated with age-related chronic diseases. These factors make the role of changes in hormonal activity difficult to disentangle and clarify in clinical practice. ${ }^{1}$ During ageing, the secretory patterns of hormones produced by the hypothalamic-pituitary axis change, as does its sensitivity to negative feedback by end hormones. The triggers that determine the ageing process in the hypothalamus and pituitary have previously been reviewed. ${ }^{2}$ In this paper, we review the response of the different components of the human endocrine system to the ageing process, including the response of the thyrotropic, somatotropic, adrenal, and gonadal axes, including bone growth, calcium, and glucose homoeostasis (figure 1).

\section{Hypothalamic-pituitary-peripheral organ axes}

\section{Thyrotropic axis}

Changes in thyroid function during ageing-Several population studies, ${ }^{3-6}$ but not all, ${ }^{7,8}$ show that after the exclusion of people with thyroid disease and people with positive anti-thyroid antibodies, normal ageing is accompanied by an increase in the concentration of serum thyroid-stimulating hormone (TSH). However, changes in TSH concentration seem to be dependent on the regional iodine status, and could reflect a survival bias. ${ }^{9}$ Free thyroxine $\left(\mathrm{FT}_{4}\right)$ concentrations remain stable with increasing age, ${ }^{4}$ although a study reported a rise in $\mathrm{FT}_{4}$ concentration with age, ${ }^{7}$ whereas free tri-iodothy-ronine $\left(\mathrm{FT}_{3}\right)$ concentrations decrease over the course of a lifespan. ${ }^{10}$ The magnitude and pattern of changes in thyroid function during ageing are highly variable amongst individuals. For instance, some people have rising TSH and $\mathrm{FT}_{4}$ concentrations, whereas others have rising TSH accompanied by falling $\mathrm{FT}_{4}$ concentrations. ${ }^{9}$ Additionally, individuals can have low $\mathrm{T}_{3}$ concentrations accompanied by high reverse $\mathrm{T}_{3}$ concentrations, reminiscent of non-thyroidal illness, whereas others have low $\mathrm{T}_{3}$ concentrations and low reverse $\mathrm{T}_{3}$ concentrations (figure 2). ${ }^{11}$ These different patterns might result from altered hormone metabolism due to disease, low-grade inflammation, or energy restriction. ${ }^{4,10,12}$ Additionally, changes can occur in TSH bioactivity with increasing age, making TSH less effective, or in the setpoint of the TSH receptor, making the receptor less functional. ${ }^{13}$ Finally, the increased prevalence of thyroid autoimmunity and autonomous nodules with increasing age can lead to altered thyroid hormone concentrations. ${ }^{3}$

\section{Clinical relevance of changes in thyroid hormone concentrations during ageing-Whether the increased prevalence of subclinical hypothyroidism and}


hyperthyroidism at an older age ${ }^{14}$ and the increase in TSH within the normal reference range during ageing is of clinical relevance remains a matter of debate. Pooled data show that subclinical hyperthyroidism is associated with an increased risk of overall and cardiovascular-related mortality, especially in older people and patients with comorbidities. ${ }^{15}$ However, a subsequent study showed that individuals aged 85 years with subclinical hyperthyroidism did not have a significantly worse 9-year survival than their euthyroid peers. ${ }^{16}$ Further, subclinical hyperthyroidism is associated with an increased risk of atrial fibrillation, ${ }^{17}$ hip and other fractures, ${ }^{18}$ and dementia, ${ }^{19}$ particularly among people with TSH concentrations that are lower than $0.10 \mathrm{mIU} / \mathrm{L}$, and those with endogenous thyroid disease. In contrast, older individuals with subclinical hypothyroidism or higher TSH concentrations within the normal range have a lower mortality than do euthyroid individuals or people with lower TSH concentrations. ${ }^{20-22}$ Although subclinical hypothyroidism in younger individuals (aged <65 years) is associated with increased risk of atherosclerosis, in older patients with TSH concentrations of up to $10 \mathrm{mIU} / \mathrm{L}$ such an association is not present.

${ }^{23}$ However, data from another meta-analysis showed that individuals aged 65-79 years with a TSH concentration above $10 \mathrm{mIU} / \mathrm{L}$ also have a greater risk of coronary heart disease, whereas this risk was not increased for those older than 80 years. ${ }^{24}$ Therefore, the higher risks found in younger individuals seem to attenuate with advancing age. Higher TSH concentrations within the reference range appear to even decrease the risk of stroke. ${ }^{25}$

These findings suggest that slightly lower hypothalamic-pituitary-thyroid axis activity is beneficial during the ageing process. This hypothesis is also supported by a series of studies that link low thyroid hormone concentrations to reduced frailty. ${ }^{26,27}$ Among older populations, lower $\mathrm{FT}_{4}$ concentrations were associated with higher physical function, ${ }^{11,28}$ whereas lower TSH concentrations predict future disability. ${ }^{16}$ This potential adaptive mechanism could also be a hereditary phenotype that contributes to longevity, since the nonagenarian offspring of centenarians were shown to have higher circulating TSH and lower thyroid hormone concentrations than did the offspring of parents who died at younger ages. ${ }^{29}$

In conclusion, the ageing process modulates the concentration of thyroid hormones. These alterations are highly variable among individuals, but overall thyroid hormone axis activity seems to decline with age, and this decline in activity is reflected by an increase in TSH and a decrease in $T_{3}$ concentrations. However, these age-associated changes are not related to a detrimental ageing process, and might even be beneficial. Therefore, age-specific hormone reference ranges are useful to avoid misclassifying and overtreating older people, although so far, these age-specific thyroid function reference ranges are still lacking.

\section{Somatotropic axis}

The hypothalamic-pituitary-somatotropic axis is a hypothalamic-pituitary axis that includes the secretion of growth hormone (somatotropin) from the somatotropes of the pituitary gland into the circulation, and the subsequent stimulation of insulin-like growth factor-1 (IGF-1). The somatopause is a gradual and progressive decrease in growth hormone secretion that occurs normally with increasing age during adult life, and is associated with an increase in adipose tissue. This decline in growth hormone after puberty continues during adult life and 
ageing, and consequently plasma growth hormone concentrations, and therefore IGF-1 concentrations, in older individuals are lower than in young adults. Age-related decline in growth hormone concentrations is well documented, consistent across different mammalian species, and primarily due to the reduced hypothalamic secretion of growth hormonereleasing hormone, causing the decline of growth hormone biosynthesis and release by the anterior pituitary. ${ }^{30,31}$ Overall, the age-dependent decrease in IGF-1 concentrations are not accompanied by elevated growth hormone concentrations, which suggests that the changes are not caused by age-dependent growth hormone resistance in the liver. ${ }^{32}$ Although the agerelated decline in the activity of the growth hormone-IGF-1 axis is considered to contribute to age-related changes that are similar to those observed in growth hormone-deficient adults, growth hormone-IGF-1 deficiency or resistance is also known to result in prolonged life expectancy, at least in animals. ${ }^{33-35}$ These data raise the question of whether or not growth hormone deficiency constitutes a beneficial adaptation to ageing, and therefore requires no therapy. Moreover, although growth hormone therapy has been shown to exert positive effects on growth hormone-deficient patients, its safety, efficacy, and role in healthy older individuals is highly controversial. ${ }^{32}$ Several mutations that decrease growth hormoneIGF-1 signalling are associated with extended longevity in mice. ${ }^{35}$ In human beings, corresponding or similar mutations have been identified, but whether these mutations alter longevity has not been established. ${ }^{35}$

Research focused on investigating brain structure and function in patients with Laron syndrome, the best characterised congenital IGF-1 deficiency, suggests that, compared with controls, older patients with Laron syndrome have brain structure and function that are consistent with those of younger adults. ${ }^{33}$ Further investigation could lead to an improved understanding of the mechanisms underlying these differences in brain structure and function, and could contribute to the identification of treatments for age-related cognitive deficits. This observation raises the possibility that growth hormone receptor inhibition has the potential to protect against age-dependent cognitive decline. ${ }^{33}$

In conclusion, ageing and the so-called somatopause are accompanied by a decrease in the concentrations of growth hormone and IGF-1, but no single intervention has been proven to be effective at halting or reversing somatopause.

\section{Control of appetite and food intake}

Appetite and food intake decrease with normal ageing, predisposing older individuals to become undernourished. Undernutrition is common in older people (aged $>65$ years), and has been implicated in the progression of chronic diseases commonly affecting older people, as well as increasing mortality. ${ }^{36}$ Understanding the factors that contribute to the decline in food intake in older people might result in effective prevention and treatment. ${ }^{37}$ Ageing affects many of the endocrine factors involved in the control of appetite and feeding, but few studies have been done in human beings to clarify these changes. Possible hormonal causes of the anorexia of ageing include increased activity of cholecystokinin, leptin, and various cytokines, and reduced activity of ghrelin. ${ }^{37}$

As early as 1999 , MacIntosh and co-workers ${ }^{38}$ reported that human ageing is associated with increased cholecystokinin concentrations. Intravenous cholecystokinin-8 infusion 
produces greater suppression of food intake in older adults than in younger individuals, indicating that sensitivity to the satiating effects of cholecystokinin is at least maintained with age, and might even increase. These results raise the possibility of using cholecystokinin antagonists as stimulants of appetite and food intake in malnourished older people. ${ }^{37}$ Central leptin resistance can increase with age, and low concentrations of circulating leptin have been observed among frail older people. ${ }^{39}$

In conclusion, ageing is accompanied by changes in ghrelin, cholecystokinin, and leptin physiology. All these changes seem to result in a significant and clinically relevant decrease in appetite. Future research will determine whether these changes can be corrected by pharmacological interventions.

\section{Adrenal axis}

Glucocorticoids-Ageing of the hypothalamic-pituitary-adrenal axis is generally associated with late-day and evening increases in cortisol concentrations, an earlier morning cortisol concentration peak, lower circadian cortisol amplitudes, and more irregular cortisol secretion patterns. ${ }^{40-43}$ Most studies, but not all, show that glucocorticoid feedback inhibition after intravenous or oral administration of glucocorticoids is reduced in older individuals. ${ }^{40}$ Similarly to the other hypothalamic-pituitary axes, whether these changes in cortisol secretion patterns are due to ageing per se, or whether these instead reflect other effects such as the presence of low-grade inflammation, impaired sleep, or changes in social or emotional status associated with ageing, remains unclear.

The changes in the hypothalamic-pituitary-adrenal axis that occur during ageing can have clinical implications. Previous studies have shown that a more dynamic activity of the axis (ie, a greater diurnal decline) relates to better physical performance ${ }^{44}$ and cognitive function in older adults than does a lower activity. ${ }^{45}$ Additionally, urinary free cortisol concentrations in the high-to-normal range are associated with an increased risk of Alzheimer's disease. ${ }^{46}$ Further, independent of disease, higher morning salivary cortisol concentrations in men and higher night salivary cortisol concentrations in women are associated with increased allcause 6 to $7 \cdot 5$-year mortality. ${ }^{47}$

Ageing can also influence tissue cortisol availability, since $11-\beta$ hydroxysteroid dehydrogenase activity, which transforms inactive cortisone into active cortisol, increases during ageing (eg, in the skin). ${ }^{48}$ This increase in cortisol availability leads to increased local glucocorticoid generation, which can cause adverse changes in older people. In muscle, for example, higher 11- $\beta$ hydroxysteroid dehydrogenase activity is associated with reduced muscle strength. ${ }^{49}$

Dehydroepiandrosterone and its sulphate-Not only does cortisol homoeostasis change with age, but also adrenal secretion of the steroid precursor dehydroepiandrosterone (DHEA) and its sulphate (DHEAS) gradually decrease over time. ${ }^{50,51}$ By the time a person reaches age 70-80 years, concentrations of DHEAS are approximately $20 \%$ of peak values in men, and $30 \%$ of peak values in women, compared with people who are younger than 40 years. ${ }^{52}$ DHEA and DHEAS are inactive precursors that are converted into androgens and oestrogens in peripheral tissue. In older men, this source of androgens is important since less 
than 50\% of these hormones are of testicular origin. Higher concentrations of DHEA and DHEAS have been associated with psychological wellbeing and improved physical functioning, including muscle strength and bone density, and with anti-inflammatory and immunoregulatory actions. ${ }^{53}$ Lower DHEAS concentrations have been associated with an increased risk of cardiovascular events and cardiovascular related mortality in people older than 50 years. ${ }^{53}$ Although the administration of $50 \mathrm{mg}$ of prasterone (ie, DHEA) per day to older individuals increases DHEAS, free and total testosterone, oestrone, oestradiol, and IGF-1 concentrations, ${ }^{54}$ this treatment has little reproducible beneficial effects on measures such as sexual function, bone density, serum lipids, or glucose concentrations. ${ }^{55}$

In conclusion, changes occur in cortisol secretion patterns during ageing. The question remains whether these alterations reflect or cause ageing-associated changes in functional ability, cognition, and mood. DHEA concentrations decrease substantially during ageing, but few data point to a clinical significance of this decrease.

\section{Gonadal axis}

Ageing of the female reproductive system-Ageing of the reproductive system in women and the accompanying hormonal changes are driven by the accelerated depletion of the ovarian pool of primordial follicles, with lower oocyte quality in the remaining follicles contributing to decreased fertility from the fourth decade of life onwards. ${ }^{56}$ The decreasing number of follicle-stimulating hormone (FSH)-sensitive antral follicles, which is proportional to the reduced reserve of primordial follicles, is reflected in the declining serum concentrations of granulosa cell-secreted anti-Müllerian hormone (a marker of ovarian reserve produced in primary, secondary, and early antral follicles), and inhibin B (a marker of ovarian activity, produced predominantly in developing antral follicles during the follicular phase of the menstrual cycle). ${ }^{57-59}$ The rapid shrinking of the ovarian reserve during reproductive life remains long unnoticed with the preservation of regular, mostly ovulatory cycles. Finally, when follicle availability becomes insufficient, cycle irregularity (>7 days longer than their previous cycles) occurs, which signals the onset of the early phase of menopausal transition, at a mean age of 46 years (range 34-54). The lengthening of cycle duration (ie, delayed dominant follicle growth or anovulatory bleeding), missed periods, and prolonged ( $\ 60$ days) intervals of amenorrhoea signal the passage to the late menopausal transition phase, ending with near total exhaustion of the ovarian follicles and the final menstrual period (after 12 months of amenorrhoea retrospectively identified as menopause) around age 51 years (range 40-60). The age at which these successive events occur varies considerably, and is influenced by body composition, ethnicity, genetics, and lifestylerelated factors. ${ }^{56}$

As menopausal transition progresses, cycles are more often anovulatory. Conversely, in ovulatory cycles, luteal phase duration and hormone concentrations remain stable throughout reproductive life and menopausal transition, with the exception of slowly declining mean progesterone concentrations. Changes in gonadotropin secretion throughout menopausal transition and after menopause, characterised by increased luteinising hormone (LH) and FSH pulse amplitude and loss of pre-ovulatory gonadotropin surges, are caused by altered feedback resulting from the intrinsically determined ovarian decline in sex steroids, 
inhibin A, and inhibin B production. ${ }^{57,58,60}$ The existence of direct age-related neuroendocrine changes, as revealed by the progressive decline of gonadotropin concentrations with advancing age after menopause, appears to be less physiologically relevant than the intrinsic ovarian changes. ${ }^{56,61}$ Throughout reproductive life and menopausal transition, there is an age-related decreasing trend of adrenal production of DHEA and DHEAS, and of mixed adrenal and ovarian production of testosterone and androstenedione. However, the LH-stimulated theca cells in the postmenopausal ovaries still contribute to circulating testosterone concentrations for up to 10 years. ${ }^{62,63}$ The multi-organ clinical consequences of the hormonal changes that occur during menopausal transition and after menopause, such as altered vasomotor regulation, bone metabolism, or urogenital status, result primarily from changes in oestrogen production. In this regard, the concentration of late postmenopausal oestrogens originating from androgen aromatisation in the peripheral tissues, although generally low compared with their concentration during the reproductive period, is still of clinical significance, as illustrated by their association with clinical correlates such as bone fractures and breast cancer, and by the occurrence of vasomotor and articular symptoms, and the increased fracture risk during pharmacological aromatase inhibition in postmenopausal women. ${ }^{64}$

Oestrogen replacement therapy can effectively inhibit the undesirable effects of menopause, such as hot flushes, accelerated bone loss, and vaginal dryness. However, the long-term riskbenefit balance remains to be determined. ${ }^{65}$

Ageing of the male reproductive system-Since many men have a well preserved sex hormone production and fertility until old age, men do not undergo an equivalent of the menopause. Nevertheless, ageing does affect the male reproductive system. ${ }^{66,67}$ Testicular volume in men older than 75 years is decreased by $30 \%$, and the number of Sertoli cells is reduced, as reflected by a modest increase in FSH concentrations and a decrease in the ratio of serum inhibin B to FSH. ${ }^{68}$ Changes in sperm quality are limited to a modest decrease in ejaculate volume and suboptimal spermatozoa motility and morphology; an increase in DNA damage also contributes to the age-related decrease in fertility. ${ }^{67,69}$ However, although these changes are attributed to ageing, they might be confounded by other factors, including increased intervals between ejaculations and health-related factors, such as obesity.

In healthy ageing men, a slow and progressive decline in morning serum testosterone concentrations of $25 \%$ takes place between age 25 and 75 years, and this is a net effect of a decreased testosterone production that is not fully compensated by reduced metabolic clearance. Additionally, sex hormone-binding globulin (SHBG) concentrations increase by about $1 \%$ per year, which causes the concentration of testosterone that is not bound to SHBG, in particular the approximately $2 \%$ of biologically active free testosterone, to more rapidly decline than total testosterone serum concentrations by approximately $50 \%$ between the ages of 25 and 75 years (figure 3) $.{ }^{67},{ }^{70}$ Normal serum (free) testosterone circadian rhythmicity, which includes higher concentrations of testosterone in the morning, is blunted. The concentration of free and total testosterone varies greatly between individuals, although approximately $20 \%$ of men aged 65 years or older have testosterone concentrations below the normal range for young men; this proportion increases with advancing age, and is greater for free testosterone than for total testosterone. ${ }^{66,67}$ 
Other male hormone concentrations also decrease with age, including total and free serum dihydrotestosterone concentrations ( $20 \%$ of which is produced in the testes, and $80 \%$ of which is converted from testosterone by $5 a$-reductase type 2 in the peripheral tissues), and serum testosterone precursor androstenedione (produced both in the testes and adrenal glands). ${ }^{66}$ Further, excretion of the urinary metabolite androstanediol glucuronide (70\% of which is converted from testosterone, and 30\% of which is converted from DHEAS) is also decreased. However, serum concentrations of oestradiol, produced by the aromatisation of testosterone and androstenedione in peripheral tissues such as fat and striated muscles, do not decrease with ageing, although serum free oestradiol concentrations might decrease. ${ }^{66,71}$

Different mechanisms contribute to the decline in serum free and total testosterone concentrations, including a progressive, although small, increase in LH and FSH concentrations, a diminished testosterone response to exogenous LH and human chorionic gonadotropin, and a reduced number of Leydig cells, all of which point towards primary testicular changes. The inadequate increase in LH concentrations in response to the reduction in free and total testosterone in many older men reveals additional changes in gonadotropin secretion, characterised by the decreased frequency of larger amplitude LH pulses, presumably resulting from the decreased hypothalamic secretion of gonadotropinreleasing hormone, since the pituitary response to exogenous gonadotropin-releasing hormone is preserved. The independent increase of hepatic SHBG production is a third factor, and is possibly the consequence of declining somatotropic axis activity. ${ }^{66,67}$ Additionally, adiposity has major confounding effects, because being overweight (BMI 25$29 \mathrm{~kg} / \mathrm{m}^{2}$ ) is associated primarily with lower SHBG and total serum testosterone concentrations than is being a healthy weight, and in obesity (BMI $230 \mathrm{~kg} / \mathrm{m}^{2}$ ) both total and free testosterone concentrations are decreased as a result of additional hypothalamic dysfunction. ${ }^{70}$

The relative contribution of ageing and both clinical and subclinical comorbidities to the changes in reproductive hormones in older men remains a matter of debate. ${ }^{66,70}$ Although many clinical features of ageing in older men are reminiscent of hypogonadism in young men, their association with sex steroid concentrations are mostly weak, with causality being difficult to demonstrate. Moreover, clinical changes may in part be the cause rather than the consequence of changed sex steroid levels ${ }^{66,67}$ low testosterone in older people is a marker of poor health, and has been linked to an increased risk of death. ${ }^{70,72}$ Sexual dysfunction is consistently associated with low serum testosterone, and even more closely associated with low serum free testosterone. The cutoff levels for the occurrence of symptoms, such as decreased libido and erectile dysfunction, are located at the lower limit of the normal range of young men-ie, total testosterone concentrations below $320 \mathrm{ng} / \mathrm{dL}(11 \mathrm{nmol} / \mathrm{L})$, and free testosterone concentrations below $6 \cdot 4 \mathrm{ng} / \mathrm{dL}(0 \cdot 22 \mathrm{nmol} / \mathrm{L}) .{ }^{66,73} \mathrm{Of}$ increasingly recognised importance is the role of testosterone as a precursor for oestradiol, which has important physiological effects in men, such as effects on bone homoeostasis. ${ }^{74}$ The reported beneficial effects of testosterone treatment on muscle, bone, sexual function, and wellbeing are essentially limited to older men who initially had low testosterone concentrations. However, these benefits appear to be modest, and long-term data on issues of concern such as prostate and cardiovascular safety are scarce. Therefore, testosterone administration to 
older men is controversial outside the context of an established organic cause of hypogonadism. $^{73,75}$

\section{Calcium and bone homoeostasis}

Advancing age represents a major risk factor for low bone mass and strength and a decline in muscle mass and function, leading to an increased risk of falls and fractures. Osteoporosis is caused by an imbalance between bone-forming osteoblasts and bone-resorbing osteoclasts, the processes of which are normally coupled and influenced by signals from osteocytes, which are embedded in mineralised bone and function as sensors of mechanical loading. ${ }^{76}$ Traditionally, oestrogen deficiency at menopause or loss of both oestrogens and androgens in older men are considered to be the main endocrine factors contributing to the development of osteoporosis. Increasing evidence now suggests, especially from studies in rodents, that fundamental intracellular processes in the bone, such as increased oxidative stress, cell senescence, inflammation, osteocyte apoptosis, DNA damage, formation of advanced glycation end products, and a decrease in autophagy, mitochondria biogenesis, vascularity, hydration of bone, and alterations in musculoskeletal progenitor cells also play important roles in the development of osteoporosis and fragility fractures with ageing. ${ }^{77-79}$

These age-related intrinsic mechanisms are coupled with changes in endocrine systems during ageing, and a higher incidence of endocrine diseases with age, including type 2 diabetes. We focus here on the major endocrine changes influencing bone.

\section{Sex steroids}

Oestrogens and androgens play important roles in the growth and maintenance of tissue mass and function in bones and muscles. Their actions on the bone result predominantly from the binding of ligands to classic sex steroid receptors, including the oestrogen receptor $\alpha$ and $\beta$ and the androgen receptor. ${ }^{74}$ For detailed information about the molecular and cellular mechanisms of action of oestrogens and androgens on bone and the contribution of oestrogen or androgen deficiency, we refer to a comprehensive review. ${ }^{80}$ The imbalance between bone formation and resorption with oestrogen deficiency affects both trabecular bone, with loss of connectivity, and cortical bone, with cortical thinning and porosity. An increase in osteocyte apoptosis occurs following the loss of ovarian or testicular function, which is mainly due to an increase in oxidative stress. ${ }^{77}$ Sex steroid deficiency could contribute to age-related bone loss, at least in part, by increasing oxidative stress and influencing the immune system. Additionally, hypogonadism is associated with the increased formation of advanced glycation end products and inflammation, thus contributing to intrinsic causes of osteoporosis that occur with ageing. In women, the potential roles of changes in progesterone, androgen, inhibins, and FSH concentrations in enhancing the effects of oestrogen deficiency on bone loss during the perimenopausal period remain to be further defined. ${ }^{81}$ In older men, oestrogen is the dominant sex steroid regulating bone resorption, and both oestrogen and testosterone are important for the maintenance of bone formation. ${ }^{82}$ In men, low serum oestradiol predicted incident fractures, but the highest risk occurred in men with additionally low testosterone and high SHBG concentrations. ${ }^{83}$ 
Sex steroids are also considered to be important in the changes in calcium and phosphate homoeostasis that occur with ageing. Postmenopausal women have higher serum phosphate concentrations than men of similar ages, and some studies have found higher serum calcium concentrations in older women than in older men, suggesting a sexual dimorphism in calcium and phosphate homoeostasis after menopause, and a potential association with sex hormone concentrations. Oestrogen has been shown to induce renal phosphate wasting and hypophosphataemia, ${ }^{84}$ to reduce renal calcium excretion, and to increase intestinal calcium absorption. ${ }^{85}$

\section{Glucocorticoids}

Osteoporosis and fractures are important side-effects of the use or an excess of glucocorticoids, and are caused by effects of glucocorticoids on bone and muscle strength. ${ }^{86}$ The generation of systemic and locally produced glucocorticoids and the sensitivity of bone cells to glucocorticoids increase with age. ${ }^{87}$ Glucocorticoids are strong inhibitors of bone formation that function, at least in part, by stimulating osteoblast and osteocyte apoptosis, ${ }^{88}$ and by suppressing the generation of new osteoblasts through the attenuation of Wnt signalling. They also increase bone resorption by promoting osteoclast survival. These combined effects can contribute to the age-related decline in bone mineral density, cortical porosity, and bone strength, and the increase in fractures. ${ }^{87}$

\section{Vitamin D, parathyroid hormone, fibroblast growth factor 23, and Klotho}

Vitamin D and its metabolites and parathyroid hormone are crucial parts of the endocrine system that control whole body calcium and phosphate homoeostasis. ${ }^{89}$ Serum vitamin D concentrations are well known to decrease with age, which can result in decreased intestinal calcium absorption and the development of secondary hyperparathyroidism. ${ }^{90}$ Circulating parathyroid hormone concentrations also appear to increase with age, independent of 25hydroxyvitamin $\mathrm{D}$, ionised calcium, phosphate, and renal function. ${ }^{91}$ Primary hyperparathyroidism, a disease most prevalent in postmenopausal women, is a well known cause of decreased bone mineral density and fractures, and is more prominent at sites with cortical bone. Secondary hyperparathyroidism can also increase fracture risk, ${ }^{90}$ as does the decline in kidney function that occurs with ageing. A previous study showed that older men and women, even without overt kidney disease, have an increased fracture risk with increasing serum phosphate concentrations, even when these are within the normal range, and independently of bone mineral density. ${ }^{92}$ Whether this increased fracture risk is directly related to serum phosphate concentration or to underlying changes in phosphate-regulating hormones, such as osteocyte-derived FGF23, a-Klotho, parathyroid hormone, or 1,25hydroxyvitamin D, remains unknown. FGF23 is a hormone secreted by osteocytes in the bone, which together with its co-factor a-Klotho inhibits phosphate reabsorption and 1,25hydroxyvitamin D production in the kidney. Defects in either a-Klotho or FGF23 gene expression cause phosphate retention and premature ageing syndrome in mice. FGF23 already begins to increase during the early stages of chronic kidney disease in response to decreased phosphate excretion, but other age-related changes in this bone-kidney endocrine system have not been well studied in human beings. ${ }^{93}$ 


\section{Growth hormone and IGF-1}

Growth hormone and its downstream mediator, IGF-1, are major determinants of peak bone mass. Declining concentrations of growth hormone and IGF-1 during ageing are associated with bone loss. Between the ages of 20 and 60 years, the IGF- 1 content in human bones declines by $60 \% .{ }^{94} \mathrm{~A}$ decline in IGF-1 and IGF-binding protein- 3 content in the bone matrix is associated with an age-related decrease in bone mineral density, and a risk of hip fractures. ${ }^{95}$

Hormone replacement therapy has been shown to decrease bone loss and fracture risk in women, but the increased risk of breast cancer and cardiovascular disease reported in the Women's Health Initiative study ${ }^{96}$ has resulted in a substantial decrease in its use. The risks of side-effects appear to depend on many factors, such as type, dose, duration of use, route of administration, timing of initiation, and whether a progestogen is used, which has led to recommendations on individualised therapy ${ }^{97}$ No large randomised controlled trials have been done to investigate the effect of growth hormone-increasing therapies or testosterone supplementation on fracture rates in men.

\section{Glucose homoeostasis}

Glucose homoeostasis is maintained by a balance between glucose ingestion, utilisation, and production, and is under tight hormonal control by insulin. Glucose homoeostasis tends towards disequilibrium with increasing chronological age. ${ }^{98,99}$ Fasting plasma glucose rises by approximately $0.055 \mathrm{mmol} / \mathrm{L}$ per decade, beginning as early as the fourth decade of life, and glucose concentrations $2 \mathrm{~h}$ after a $75 \mathrm{~g}$ oral glucose tolerance test also gradually increase (Egan JM, unpublished; figure 4). No data have been shown to support alterations in glucose ingestion with age. Another important consideration is that impairment of cerebral glucose metabolism might precede histological findings in Alzheimer's disease, and probably exacerbates its pathology.

\section{Reduced pulsatility and decreased insulin action}

Insulin is secreted in a pulsatile manner comprising two stereotypical pulses: high frequency pulses with a pulse interval of about 6 min, and ultradian pulses with a pulse interval of approximately 90 min. ${ }^{100-102}$ Pulsatile secretion accounts for at least $70 \%$ of secreted insulin. ${ }^{103}$ Total and pulsatile insulin secretion is abnormal in people with type 2 diabetes, being both deficient and chaotic. ${ }^{104}$ However, even healthy older individuals have disordered insulin secretion with a characteristic reduction in both amplitude and number of high frequency pulses, and a reduced frequency of ultradian pulses in both the basal and stimulated state. ${ }^{105,106}$

The liver is exposed to insulin pulses from the islets directly through the portal vein. Insulin is subject to degradation during first pass, thereby dampening the amplitude of the pulses arriving at peripheral tissues. Insulin receptor trafficking upon activation is dynamic, and dephosphorylated insulin receptor is recycled to the cell surface, a process that is synchronous with the pulsatility of insulin secretion. ${ }^{107}$ Consequently, insulin is less effective in suppressing hepatic glucose production when it is delivered to the liver in a 
disordered manner than when delivered normally. Additionally, insulin clearance in the liver is said to be increased in older people. ${ }^{108}$

\section{Effect of age on glucose disposal}

Whether ageing is responsible for the gradual deterioration in glucose disposal across the human lifespan (figure 4B) is a matter of ongoing debate because of confounding physical changes that occur in the body over time. In humans beings, the majority of the glucose in an oral glucose load is disposed into muscle, glucose concentrations after glucose ingestion gradually rise with age (figure 4), and glucose disposal becomes slower over the course of a lifetime. Studies using hyperglycaemic clamps show that this slowing in glucose disposal is probably not due to diminished total insulin secretion in response to the rising glucose. ${ }^{109}$ The progressive decline in insulin action with age can be attributed largely to gradual increases in the percentage of total body, especially visceral, fat, and to the changing ratio of fat to lean muscle mass. The degree of relative obesity and the site of fat deposition appear to be the crucial variables determining the efficacy of insulin action. ${ }^{10,111}$ These factors are in turn influenced by total caloric intake, decreasing physical activity, medications, and illnesses. ${ }^{112}$ However, although exercise improves insulin action and slows the onset of diabetes, no evidence shows that exercise reverses age-related changes occurring in $\beta$ cells.

\section{Diabetes in older people}

There is a continuum of risk for the development of diabetes, coupled with underlying genetic and environmental factors unique to each individual, although the risk of developing diabetes seems to reach a plateau or even decline after age 85 years. ${ }^{113}$ In older people, $\beta$ cell dysfunction and deficiency play a greater role in the pathophysiology of diabetes than in younger adults, and insulin resistance in muscle increases even in the absence of obesity in some individuals. ${ }^{114,115}$ The prevalence of diabetes varies depending on the criteria used. At least $25 \%$ of people older than 65 years have diabetes, ${ }^{116,117}$ which can be detected only on the basis of a $2 \mathrm{~h}$ oral glucose tolerance test ( $\geq 11.1 \mathrm{mmol} / \mathrm{L}$ ) in $58 \%$ of people. ${ }^{118,119}$ However, an oral glucose tolerance test is not the standard recommendation for diabetes screening. $\mathrm{HbA}_{1 \mathrm{c}}$ concentration testing, which is recommended due to ease of testing ( $12 \mathrm{~h}$ fasting not required), can detect $14.5 \%$ of undiagnosed cases ( $26.5 \%[48 \mathrm{mmol} / \mathrm{mol}]),{ }^{120} \mathrm{but}$ the addition of fasting plasma glucose concentration ( $27 \mathrm{mmol} / \mathrm{L}$ ) testing to $\mathrm{HbA}_{1 \mathrm{c}}$ increases detection to $42 \%$ of undiagnosed cases. Therefore, even when using both $\mathrm{HbA}_{1 \mathrm{c}}$ and fasting plasma glucose to diagnose diabetes, the majority of people with diabetes who are aged 65 years and older will remain undiagnosed. The low detection in older people with these easily available diagnostic tests mean that the prevention of diabetes progression and complications due to glucose disequilibrium is often delayed. Additionally, because the pathophysiology of diabetes can be different in younger patients compared with those who are older-eg, severe insulin resistance with obesity can be a more prominent factor in younger patients-increased attention to treatment individualisation is required given the heterogeneity of the older population and their underlying conditions. Most clinicians would agree that healthy older people, similarly to younger people, should have diabetes screening, and if prediabetes is uncovered, lifestyle intervention tailored to the patient could prevent the development of diabetes with its accompanying microvascular and macrovascular complications, given the presumed increased in life expectancy for all populations. ${ }^{121}$ 
Similar screening would not apply to someone with severe functional limitations or Alzheimer's disease.

\section{Conclusions}

Changes in the activities of various endocrine systems occur during ageing, including altered hormonal secretory patterns and modulation of feedback sensitivity, summarised in figure 1 . These physiological changes should be considered when interpreting hormone concentrations in older individuals with and without endocrine disease. However, the magnitude of these changes varies considerably between individuals, and reference values for hormone concentrations at older ages should be established. Differentiating whether these changes are due to the ageing process, or whether they are related to other processes, such as intercurrent chronic diseases, inflammation, nutritional status, or a combination of these, is difficult. The effect of these age-related changes on body composition, physical function, emotional wellbeing, morbidity, and finally mortality is only partly known. Some of the changes could be a beneficial adaptation to ageing, whereas others are not. Future studies should aim to explore whether endocrine alterations are maladaptive or adaptive to ageing.

\section{References}

1. Kennedy BK, Berger SL, Brunet A, et al. Geroscience: linking aging to chronic disease. Cell 2014; 159: 709-13.25417146

2. Cavadas C, Aveleira CA, Souza GF, Velloso LA. The pathophysiology of defective proteostasis in the hypothalamus-from obesity to ageing. Nat Rev Endocrinol 2016; 12: 723-33.27388987

3. Surks MI , Ortiz E , Daniels GH , et al. Subclinical thyroid disease: scientific review and guidelines for diagnosis and management. JAMA 2004; 291: 228-38.14722150

4. Bremner AP, Feddema P, Leedman PJ , et al. Age-related changes in thyroid function: a longitudinal study of a community-based cohort. J Clin Endocrinol Metab 2012; 97: 155462.22344200

5. Waring AC, Arnold AM, Newman AB , Buzkova P, Hirsch C , Cappola AR . Longitudinal changes in thyroid function in the oldest old and survival: the cardiovascular health study all-stars study. J Clin Endocrinol Metab 2012; 97: 3944-50.22879629

6. Bjergved L, Jorgensen T, Perrild H, et al. Predictors of change in serum TSH after iodine fortification: an 11-year follow-up to the DanThyr study. J Clin Endocrinol Metab 2012; 97: 402229.22962423

7. Chaker L, Korevaar TI , Medici M , et al. Thyroid function characteristics and determinants: the Rotterdam Study. Thyroid 2016; 26: 1195-204.27484151

8. Hoogendoorn EH, Hermus AR, de Vegt F, et al. Thyroid function and prevalence of antithyroperoxidase antibodies in a population with borderline sufficient iodine intake: influences of age and sex. Clin Chem 2006; 52: 104-11.16254196

9. Mammen JS , McGready J, Ladenson PW, Simonsick EM . Unstable thyroid function in older adults is caused by alterations in both thyroid and pituitary physiology and is associated with increased mortality. Thyroid 2017; 27: 1370-7728854871

10. Strich D , Karavani G, Edri S , Gillis D . TSH enhancement of FT4 to FT3 conversion is age dependent. Eur J Endocrinol 2016; 175: 49-54.27150496

11. van den Beld AW, Visser TJ, Feelders RA, Grobbee DE, Lamberts SW . Thyroid hormone concentrations, disease, physical function, and mortality in elderly men. J Clin Endocrinol Metab 2005; 90: 6403-09.16174720 
12. Burman KD , Smallridge RC, Osburne R, et al. Nature of suppressed TSH secretion during undernutrition: effect of fasting and refeeding on TSH responses to prolonged TRH infusions. Metabolism 1980; 29: 46-52.6766202

13. Klug TL, Adelman RC . Age-dependent accumulation of an immunoreactive species of thyrotropin (TSH) which inhibits production of thyroid hormones [proceedings]. Adv Exp Med Biol 1978; 97: 259-64.645474

14. Veltri F, Rocha FO, Willems D, et al. Prevalence of thyroid dysfunction and autoimmunity in the older population and implications of age-specific reference ranges. Clin Chim Acta 2017; 465: 3439.27988318

15. Biondi B , Bartalena L, Cooper DS , Hegedüs L . Laurberg P, Kahaly GJ. The 2015 European Thyroid Association guidelines on diagnosis and treatment of endogenous subclinical hyperthyroidism. Eur Thyroid J 2015; 4: 149-63.26558232

16. Pearce SH , Razvi S, Yadegarfar ME, et al. Serum thyroid function, mortality and disability in advanced old age: the Newcastle 85+ study. J Clin Endocrinol Metab 2016; 101: 438594.27552542

17. Selmer C, Olesen JB , Hansen ML, et al. The spectrum of thyroid disease and risk of new onset atrial fibrillation: a large population cohort study. BMJ 2012; 345: e7895.23186910

18. Segna D, Bauer DC, Feller M , et al. Association between subclinical thyroid dysfunction and change in bone mineral density in prospective cohorts. J Intern Med 2018; 283: 56-72.29034571

19. Rieben C, Segna D, da Costa BR, et al. Subclinical thyroid dysfunction and the risk of cognitive decline: a meta-analysis of prospective cohort studies. J Clin Endocrinol Metab 2016; 101: 494554.27689250

20. Ceresini G , Morganti S, Rebecchi I, et al. Evaluation of the circadian profiles of serum dehydroepiandrosterone (DHEA), cortisol, and cortisol/DHEA molar ratio after a single oral administration of DHEA in elderly subjects. Metabolism 2000; 49: 548-51.10778884

21. Selmer C, Olesen JB , Hansen ML, et al. Subclinical and overt thyroid dysfunction and risk of allcause mortality and cardiovascular events: a large population study. J Clin Endocrinol Metab 2014; 99: 2372-82.24654753

22. Atzmon G, Barzilai N, Surks MI, Gabriely I . Genetic predisposition to elevated serum thyrotropin is associated with exceptional longevity. J Clin Endocrinol Metab 2009; 94: 476875.19837933

23. Hennessey JV , Espaillat R . Diagnosis and management of subclinical hypothyroidism in elderly adults: a review of the literature. J Am Geriatr Soc 2015; 63: 1663-73.26200184

24. Rodondi N, den Elzen WP , Bauer DC, et al. Subclinical hypothyroidism and the risk of coronary heart disease and mortality. JAMA 2010; 304: 1365-74.20858880

25. Chaker L, Baumgartner C, den Elzen WP, et al. Thyroid function within the reference range and the risk of stroke: an individual participant data analysis. J Clin Endocrinol Metab 2016; 101 : 4270-82.27603906

26. Virgini VS , Rodondi N , Cawthon PM , et al. Subclinical thyroid dysfunction and frailty among older men. J Clin Endocrinol Metab 2015; 100: 4524-32.26495751

27. Bano A, Chaker L, Schoufour J, et al. High circulating free thyroxine levels may increase the risk of frailty: the Rotterdam Study. J Clin Endocrinol Metab 2018; 103: 328-35.29126162

28. Simonsick EM , Chia CW , Mammen JS , Egan JM , Ferrucci L . Free thyroxine and functional mobility, fitness, and fatigue in euthyroid older men and women in the Baltimore longitudinal study of aging. J Gerontol A Biol Sci Med Sci 2016; 71: 961-6726791089

29. Bowers J , Terrien J , Clerget-Froidevaux MS , et al. Thyroid hormone signaling and homeostasis during aging. Endocr Rev 2013; 34: 556-89.23696256

30. Di Somma C , Brunelli V , Savanelli MC , et al. Somatopause: state of the art. Minerva Endocrinol 2011; 36: 243-55.22019753

31. Ceda GP , Dall'Aglio E, Morganti S , et al. Update on new therapeutic options for the somatopause. Acta Biomed Ateneo Parmense 2010; 81 (suppl 1): 67-72.

32. Giordano R, Bonelli L, Marinazzo E , Ghigo E , Arvat E . Growth hormone treatment in human ageing: benefits and risks. Hormones (Athens) 2008; 7: 133-39.18477550 
33. Nashiro K, Guevara-Aguirre J , Braskie MN , et al. Brain structure and function associated with younger adults in growth hormone receptor-deficient humans. J Neurosci 2017; 37: 1696707.28073935

34. Laron Z, Kauli R , Lapkina L, Werner H . IGF-I deficiency, longevity and cancer protection of patients with Laron syndrome. Mutat Res Rev Mutat Res 2017; 772: 123-33.28528685

35. Junnila RK , List EO , Berryman DE , Murrey JW , Kopchick JJ . The GH/IGF-1 axis in ageing and longevity. Nat Rev Endocrinol 2013; 9: 366-76.23591370

36. Cruz-Jentoft AJ , Kiesswetter E , Drey M, Sieber CC . Nutrition, frailty, and sarcopenia. Aging Clin Exp Res 2017; 29: 43-48.28155181

37. Chapman IM . Endocrinology of anorexia of ageing. Best Pract Res Clin Endocrinol Metab 2004; 18: 437-52.15261848

38. MacIntosh CG, Andrews JM , Jones KL, et al. Effects of age on concentrations of plasma cholecystokinin, glucagon-like peptide 1, and peptide YY and their relation to appetite and pyloric motility. Am J Clin Nutr 1999; 69: 999-1006.10232642

39. Fried LP , Tangen CM , Walston J , et al. Frailty in older adults: evidence for a phenotype. J Gerontol A Biol Sci Med Sci 2001; 56: M146-56.11253156

40. Veldhuis JD, Sharma A, Roelfsema F . Age-dependent and gender-dependent regulation of hypothalamic-adrenocorticotropic-adrenal axis. Endocrinol Metab Clin North Am 2013; 42: 20125.23702398

41. Nater UM , Hoppmann CA, Scott SB . Diurnal profiles of salivary cortisol and alpha-amylase change across the adult lifespan: evidence from repeated daily life assessments. Psychoneuroendocrinology 2013; 38: 3167-71.24099860

42. Almeida DM , Piazza JR , Stawski RS . Interindividual differences and intraindividual variability in the cortisol awakening response: an examination of age and gender. Psychol Aging 2009; 24: 819-2720025398

43. Dmitrieva NO, Almeida DM , Dmitrieva J , Loken E, Pieper CF . A day-centered approach to modeling cortisol: diurnal cortisol profiles and their associations among U.S. adults. Psychoneuroendocrinology 2013; 38: 2354-65.23770247

44. Gardner MP , Lightman S , Sayer AA, et al. Dysregulation of the hypothalamic pituitary adrenal (HPA) axis and physical performance at older ages: an individual participant meta-analysis. Psychoneuroendocrinology 2013; 38: 40-49.22658392

45. Dijckmans B , Tortosa-Martinez J , Caus N, et al. Does the diurnal cycle of cortisol explain the relationship between physical performance and cognitive function in older adults? Eur Rev Aging Phys Act 2017; 14: 6.28515793

46. Ennis GE, An Y, Resnick SM , Ferrucci L , O’Brien RJ , Moffat SD . Long-term cortisol measures predict Alzheimer disease risk. Neurology 2017; 88: 371-78.27986873

47. Schoorlemmer RM, Peeters GM, van Schoor NM , Lips P . Relationships between cortisol level, mortality and chronic diseases in older persons. Clin Endocrinol (Oxf) 2009; 71: 779_ 86.19226268

48. Tiganescu A, Walker EA, Hardy RS , Mayes AE, Stewart PM . Localization, age- and sitedependent expression, and regulation of 11 beta-hydroxysteroid dehydrogenase type 1 in skin. $\mathrm{J}$ Invest Dermatol 2011; 131: 30-36.20739946

49. Kilgour AH , Gallagher IJ , MacLullich AM , et al. Increased skeletal muscle 11betaHSD1 mRNA is associated with lower muscle strength in ageing. PLoS One 2013; 8: e84057.24391882

50. Herbert J The age of dehydroepiandrosterone. Lancet 1995; 345: 1193-94.7739304

51. Ferrari E, Arcaini A, Gornati R, et al. Pineal and pituitary-adrenocortical function in physiological aging and in senile dementia. Exp Gerontol 2000; 35: 1239-50.11113605

52. Ravaglia G, Forti P, Maioli F, et al. The relationship of dehydroepiandrosterone sulfate (DHEAS) to endocrine-metabolic parameters and functional status in the oldest-old. Results from an Italian study on healthy free-living over-ninety-year-olds. J Clin Endocrinol Metab 1996; 81: 117378.8772596

53. Ohlsson C , Vandenput L, Tivesten A . DHEA and mortality: what is the nature of the association? J Steroid Biochem Mol Biol 2015; 145: 248-53.24704256 
54. Baulieu EE, Thomas G, Legrain S, et al. Dehydroepiandrosterone (DHEA), DHEA sulfate, and aging: contribution of the DHEAge Study to a sociobiomedical issue. Proc Natl Acad Sci USA 2000; 97: 4279-84.10760294

55. Elraiyah T, Sonbol MB , Wang Z, et al. The benefits and harms of systemic dehydroepiandrosterone (DHEA) in postmenopausal women with normal adrenal function: a systematic review and meta-analysis. J Clin Endocrinol Metab 2014; 99: 3536-42.25279571

56. Broekmans FJ , Soules MR , Fauser BC . Ovarian aging: mechanisms and clinical consequences. Endocr Rev 2009; 30: 465-93.19589949

57. Hale GE, Zhao X, Hughes CL, Burger HG, Robertson DM, Fraser IS . Endocrine features of menstrual cycles in middle and late reproductive age and the menopausal transition classified according to the Staging of Reproductive Aging Workshop (STRAW) staging system. J Clin Endocrinol Metab 2007; 92: 3060-67.17550960

58. Santoro N , Randolph JF . Reproductive hormones and the menopause transition. Obstet Gynecol Clin North Am 2011; 38: 455-66.21961713

59. Broer SL, Eijkemans MJ , Scheffer GJ , et al. Anti-mullerian hormone predicts menopause: a long-term follow-up study in normoovulatory women. J Clin Endocrinol Metab 2011; 96: 2532 39.21613357

60. Vanden Brink H, Robertson DM, Lim H, et al. Associations between antral ovarian follicle dynamics and hormone production throughout the menstrual cycle as women age. J Clin Endocrinol Metab 2015; 100: 4553-62.26465392

61. Shaw ND, Srouji SS , Histed SN, Hall JE . Differential effects of aging on estrogen negative and positive feedback. Am J Physiol Endocrinol Metab 2011; 301: E351-55.21558550

62. Davison SL, Bell R, Donath S, Montalto JG, Davis SR . Androgen levels in adult females: changes with age, menopause, and oophorectomy. J Clin Endocrinol Metab 2005; 90: 384753.15827095

63. Fogle RH , Stanczyk FZ, Zhang X, Paulson RJ . Ovarian androgen production in postmenopausal women. J Clin Endocrinol Metab 2007; 92: 3040-43.17519304

64. Lonning PE, Eikesdal HP . Aromatase inhibition 2013: clinical state of the art and questions that remain to be solved. Endocr Relat Cancer 2013; 20: R183-201.23625614

65. Stuenkel CA, Davis SR, Gompel A, et al. Treatment of symptoms of the menopause: an endocrine society clinical practice guideline. J Clin Endocrinol Metab 2015; 100: 39754011.26444994

66. Kaufman JM, Vermeulen A. The decline of androgen levels in elderly men and its clinical and therapeutic implications. Endocr Rev 2005; 26: 833-76.15901667

67. Basaria S Reproductive aging in men. Endocrinol Metab Clin North Am 2013; 42: 255 70.23702400

68. Mahmoud AM, Goemaere S, El-Garem Y, Van Pottelbergh I, Comhaire FH, Kaufman JM . Testicular volume in relation to hormonal indices of gonadal function in community-dwelling elderly men. J Clin Endocrinol Metab 2003; 88: 179-84.12519849

69. Sartorius GA , Nieschlag E . Paternal age and reproduction. Hum Reprod Update 2010; 16: 6579.19696093

70. Wu FC, Tajar A, Pye SR, et al. Hypothalamic-pituitary-testicular axis disruptions in older men are differentially linked to age and modifiable risk factors: the European Male Aging Study. J Clin Endocrinol Metab 2008; 93: 2737-45.18270261

71. Hsu B , Cumming RG, Hirani V , et al. Temporal trend in androgen status and androgen-sensitive outcomes in older men. J Clin Endocrinol Metab 2016; 101: 1836-46.26918290

72. Araujo AB , Dixon JM , Suarez EA, Murad MH , Guey LT , Wittert GA . Clinical review: endogenous testosterone and mortality in men: a systematic review and meta-analysis. J Clin Endocrinol Metab 2011; 96: 3007-19.21816776

73. Snyder PJ , Bhasin S, Cunningham GR, et al. Effects of testosterone treatment in older men. N Engl J Med 2016; 374: 611-24.26886521

74. Manolagas SC, O'Brien CA, Almeida M. The role of estrogen and androgen receptors in bone health and disease. Nat Rev Endocrinol 2013; 9: 699-712.24042328 
75. Orwoll ES . Establishing a framework-does testosterone supplementation help older men? N Engl J Med 2016; 374: 682-83.26886526

76. Seeman E, Delmas PD . Bone quality - the material and structural basis of bone strength and fragility. N Engl J Med 2006; 354: 2250-61.16723616

77. Manolagas SC . From estrogen-centric to aging and oxidative stress: a revised perspective of the pathogenesis of osteoporosis. Endocr Rev 2010; 31: 266-300.20051526

78. Onal M, Piemontese M, Xiong J , et al. Suppression of autophagy in osteocytes mimics skeletal aging. J Biol Chem 2013; 288: 17432-40.23645674

79. Kassem M , Marie PJ . Senescence-associated intrinsic mechanisms of osteoblast dysfunctions. Aging Cell 2011; 10: 191-97.21210937

80. Almeida M , Laurent MR , Dubois V , et al. Estrogens and androgens in skeletal physiology and pathophysiology. Physiol Rev 2017; 97: 135-8727807202

81. Khosla S Pathogenesis of age-related bone loss in humans. J Gerontol A Biol Sci Med Sci 2013; 68: 1226-35.22923429

82. Falahati-Nini A , Riggs BL, Atkinson EJ , O’Fallon WM , Eastell R , Khosla S . Relative contributions of testosterone and estrogen in regulating bone resorption and formation in normal elderly men. J Clin Invest 2000; 106: 1553-60.11120762

83. Orwoll ES , Lapidus J , Wang PY, et al. The limited clinical utility of testosterone, estradiol, and sex hormone binding globulin measurements in the prediction of fracture risk and bone loss in older men. J Bone Miner Res 2017; 32: 633-40.27753150

84. Faroqui S , Levi M, Soleimani M , Amlal H . Estrogen downregulates the proximal tubule type IIa sodium phosphate cotransporter causing phosphate wasting and hypophosphatemia. Kidney Int 2008; 73: 1141-50.18305465

85. Dick IM , Devine A, Beilby J , Prince RL . Effects of endogenous estrogen on renal calcium and phosphate handling in elderly women. Am J Physiol Endocrinol Metab 2005; 288: E430 35.15466921

86. Sato AY, Richardson D, Cregor M, et al. Glucocorticoids induce bone and muscle atrophy by tissue-specific mechanisms upstream of E3 ubiquitin ligases. Endocrinology 2017; 158: 664 7728359087

87. Almeida M , O’Brien CA . Basic biology of skeletal aging: role of stress response pathways. J Gerontol A Biol Sci Med Sci 2013; 68:1197-208.23825036

88. Weinstein RS , Manolagas SC . Apoptosis and osteoporosis. Am J Med 2000; 108: $153-$ 64.11126309

89. Fleet JC . The role of vitamin D in the endocrinology controlling calcium homeostasis. Mol Cell Endocrinol 2017; 453: 36-45.28400273

90. Bruce DG , St John A , Nicklason F , Goldswain PR . Secondary hyperparathyroidism in patients from Western Australia with hip fracture: relationship to type of hip fracture, renal function, and vitamin D deficiency. J Am Geriatr Soc 1999; 47: 354-59.10078900

91. Carrivick SJ , Walsh JP, Brown SJ , Wardrop R , Hadlow NC . Brief report: does PTH increase with age, independent of 25 -hydroxyvitamin $\mathrm{D}$, phosphate, renal function, and ionized calcium? J Clin Endocrinol Metab 2015; 100: 2131-34.25751107

92. Campos-Obando N, Koek WNH, Hooker ER, et al. Serum phosphate is associated with fracture risk: the Rotterdam Study and MrOS. J Bone Miner Res 2017; 32: 1182-93.28177140

93. Martin A, David V, Quarles LD . Regulation and function of the FGF23/klotho endocrine pathways. Physiol Rev 2012; 92: 131-55.22298654

94. Seck T , Scheppach B , Scharla S , et al. Concentration of insulin-like growth factor (IGF)-I and -II in iliac crest bone matrix from pre- and postmenopausal women: relationship to age, menopause, bone turnover, bone volume, and circulating IGFs. J Clin Endocrinol Metab 1998; 83: 2331379661604

95. Garnero P, Sornay-Rendu E , Delmas PD . Low serum IGF-1 and occurrence of osteoporotic fractures in postmenopausal women. Lancet 2000; 355: 898-99.10752709

96. Manson JE, Aragaki AK, Rossouw JE, et al. Menopausal hormone therapy and long-term allcause and cause-specific mortality: the Women's Health Initiative Randomized Trials. JAMA 2017; 318: 927-38.28898378 
97. The NAMS 2017 Hormone Therapy Position Statement Advisory Panel. The 2017 hormone therapy position statement of The North American Menopause Society. Menopause 2017; 24: 728-53.28650869

98. Reaven GM , Chen N, Hollenbeck C, Chen YD . Effect of age on glucose tolerance and glucose uptake in healthy individuals. J Am Geriatr Soc 1989; 37: 735-40.2666485

99. Broughton DL, Taylor R . Review: deterioration of glucose tolerance with age: the role of insulin resistance. Age Ageing 1991; 20: 221-25.1853796

100. Polonsky KS , Given BD, Van Cauter E . Twenty-four-hour profiles and pulsatile patterns of insulin secretion in normal and obese subjects. J Clin Invest 1988; 81: 442-48.3276730

101. Lang DA, Matthews DR, Peto J , Turner RC . Cyclic oscillations of basal plasma glucose and insulin concentrations in human beings. N Engl J Med 1979; 301: 1023-27386121

102. Matveyenko AV , Liuwantara D , Gurlo T , et al. Pulsatile portal vein insulin delivery enhances hepatic insulin action and signaling. Diabetes 2012; 61: 2269-79.22688333

103. Porksen N , Munn S , Steers J , Vore S, Veldhuis J , Butler P . Pulsatile insulin secretion accounts for $70 \%$ of total insulin secretion during fasting. Am J Physiol 1995; 269: E478-88.7573425

104. Lang DA, Matthews DR , Burnett M , Turner RC . Brief, irregular oscillations of basal plasma insulin and glucose concentrations in diabetic man. Diabetes 1981; 30: 435-39.7014311

105. Meneilly GS , Ryan AS , Veldhuis JD , Elahi D . Increased disorderliness of basal insulin release, attenuated insulin secretory burst mass, and reduced ultradian rhythmicity of insulin secretion in older individuals. J Clin Endocrinol Metab 1997; 82: 4088-93.9398719

106. Meneilly GS, Veldhuis JD, Elahi D . Disruption of the pulsatile and entropic modes of insulin release during an unvarying glucose stimulus in elderly individuals. J Clin Endocrinol Metab 1999; 84: 1938-3.10372690

107. Hori SS , Kurland IJ , DiStefano JJ . Role of endosomal trafficking dynamics on the regulation of hepatic insulin receptor activity: models for Fao cells. Ann Biomed Eng 2006; 34: 87992.16708271

108. Basu R , Dalla Man C , Campioni M , et al. Effects of age and sex on postprandial glucose metabolism: differences in glucose turnover, insulin secretion, insulin action, and hepatic insulin extraction. Diabetes 2006; 55: 2001-14.16804069

109. Elahi D, Muller DC, McAloon-Dyke M , Tobin JD, Andres R. The effect of age on insulin response and glucose utilization during four hyperglycemic plateaus. Exp Gerontol 1993; 28: 393-409.8224037

110. Cefalu WT, Wang ZQ, Werbel S, et al. Contribution of visceral fat mass to the insulin resistance of aging. Metabolism 1995; 44: 954-59.7616857

111. Coon PJ , Rogus EM, Drinkwater D, Muller DC, Goldberg AP . Role of body fat distribution in the decline in insulin sensitivity and glucose tolerance with age. J Clin Endocrinol Metab 1992; 75: $1125-32.1400882$

112. Kahn SE, Larson VG, Beard JC, et al. Effect of exercise on insulin action, glucose tolerance, and insulin secretion in aging. Am J Physiol 1990; 258: E937-43.2193534

113. McBean AM , Li S , Gilbertson DT , Collins AJ . Differences in diabetes prevalence, incidence, and mortality among the elderly of four racial/ethnic groups: whites, blacks, hispanics, and asians. Diabetes Care 2004; 27: 2317-24.15451894

114. Petersen KF , Befroy D, Dufour S, et al. Mitochondrial dysfunction in the elderly: possible role in insulin resistance. Science 2003; 300: 1140-42.12750520

115. Meneilly GS , Elahi D . Metabolic alterations in middle-aged and elderly lean patients with type 2 diabetes. Diabetes Care 2005; 28: 1498-99.15920078

116. Centers for Disease Control and Prevention. National diabetes statistics report, 2017 https:// www.cdc.gov/diabetes/pdfs/data/statistics/national-diabetes-statistics-report.pdf (accessed Sept 1, 2017).

117. Diabetes UK . Facts and stats 2016 https://diabetes-resources-production.s3-euwest-1.amazonaws.com/diabetes-storage/migration/pdf/DiabetesUK_Facts_Stats_Oct16.pdf (accessed Sept 1, 2017). 
118. Cowie CC, Rust KF, Byrd-Holt DD, et al. Prevalence of diabetes and high risk for diabetes using A1C criteria in the U.S. population in 1988-2006. Diabetes Care 2010; 33: 56268.20067953

119. Chia CW , Ferrucci L . A look at the trend in diabetes-related complications in the U.S. over the past two decades: looking ahead. Ann Trans Med 2014; 2: 121.

120. American Diabetes Association. Classification and diagnosis of diabetes. Diabetes Care 2018; 40 (suppl 1): S13-27

121. Diabetes Prevention Program Research Group. Reduction in the incidence of type 2 diabetes with lifestyle intervention or metformin. N Engl J Med 2002; 346: 393-403.11832527 


\section{Search strategy and selection criteria}

We searched the Cochrane Library, MEDLINE, and Embase from their inception up until Nov 14, 2017. We used the search terms "pituitary", "thyroid", "adrenal", "growth hormone", "IGF-I", "receptor sensitivity", "testosterone", "oestradiol”, "glucose", and "insulin" in combination with the term "aging". Additionally, we used the terms "osteoporosis" or "skeletal aging" or "bone-aging" in combination with the terms "endocrinology" or "hormones". The search was restricted to articles that were published in English. We largely selected publications from the past 5 years, but also included commonly referenced and highly regarded older publications. We also searched the reference lists of articles identified by this search strategy and selected those we judged relevant. We have cited review articles to provide readers with more details and references than this paper has room for. Our reference list was modified on the basis of comments from peer reviewers. 


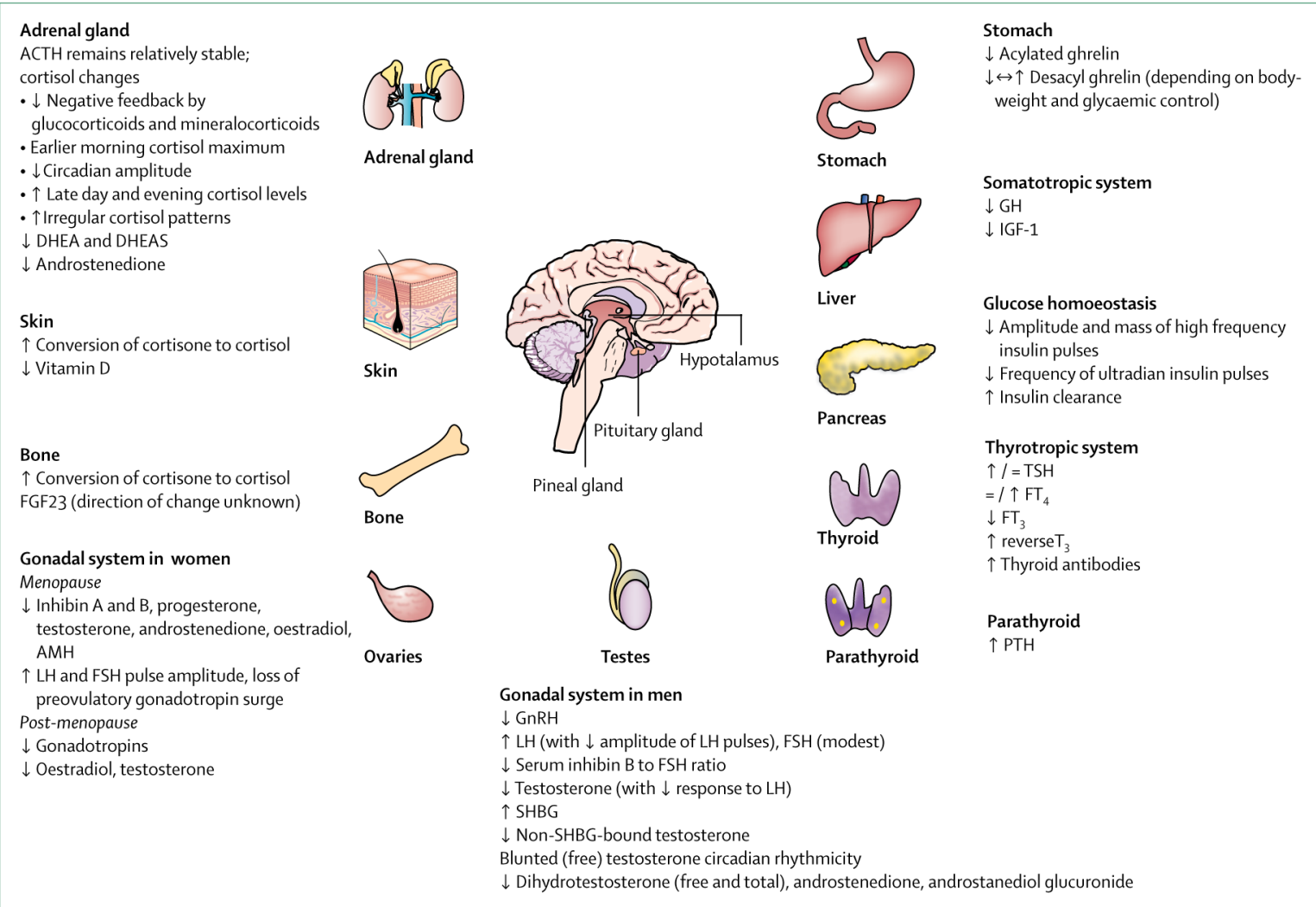

Figure 1: Most-reported changes in circulating hormone concentrations and hormone profiles with ageing

$\mathrm{ACTH}=$ adrenocorticotropic hormone. DHEA=dehydroepiandrostenedione. DHEAS=DHEA sulphate. FGF23=fibroblast growth factor 23. AMH=anti-Müllerian hormone.

LH=luteinising hormone. FSH=follicle-stimulating hormone. GnRH=gonadotropinreleasing hormone. $\mathrm{SHBG}=$ sex hormone binding globulin. $\mathrm{GH}=$ growth hormone. IGF-1=insulin-like growth factor 1 . TSH=thyroid-stimulating hormone. FT4=free thyroxine (T4). FT3=free tri-iodothyronine (T3). PTH=parathyroid hormone. 


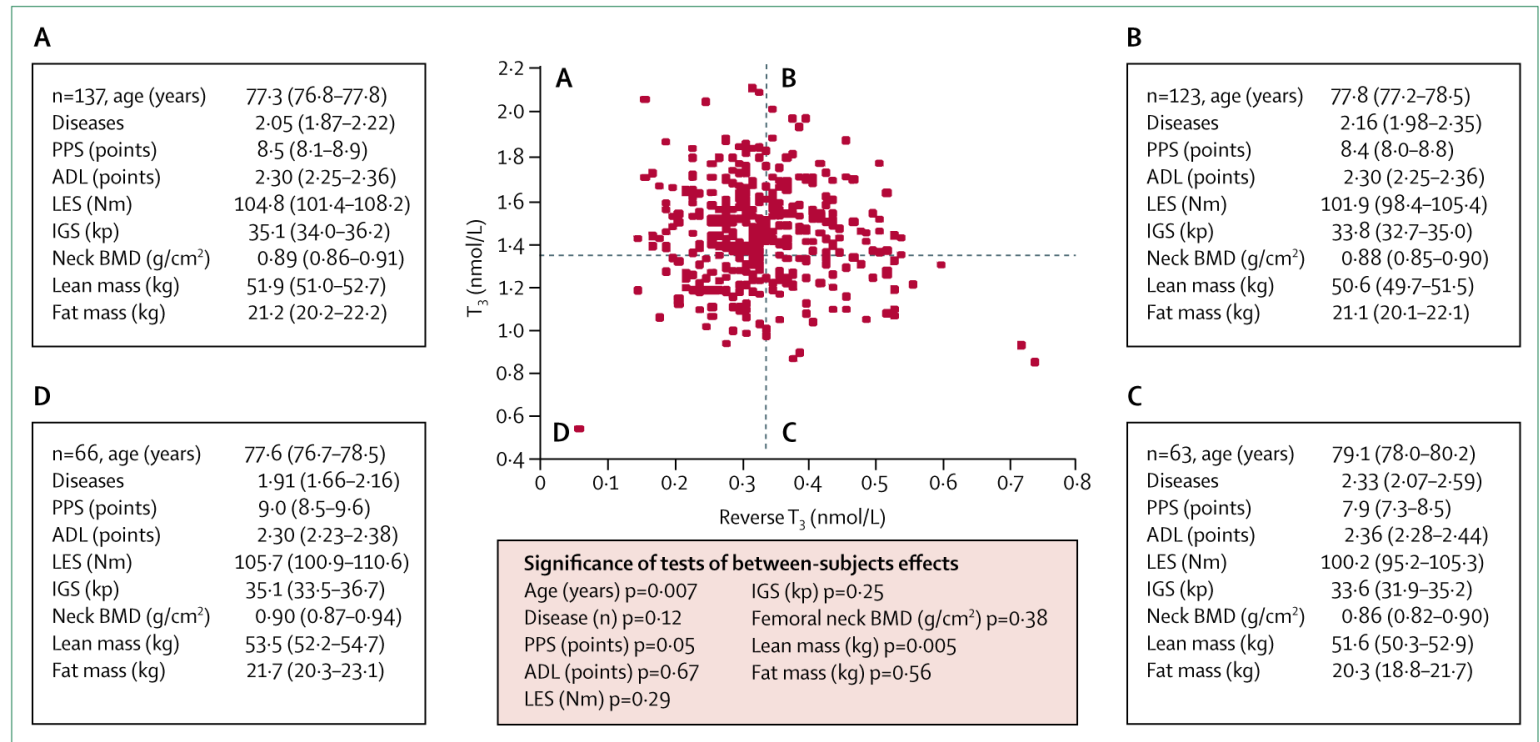

Figure 2: Concentrations of $\mathbf{T}_{3}$ and $\mathbf{r} \mathbf{T}_{3}$ within a population of 403 elderly men Each datapoint represents one of a cohort of 403 men aged 73-94 years living in the Netherlands. ${ }^{11}$ The dotted lines indicate the normal concentrations of $\mathrm{T}_{3}$ and $\mathrm{rT}_{3}$. Number of participants, mean age, mean number of diseases, and mean values for various other measures of physical performance are provided for each quadrant, with accompanying $95 \%$ CIs. T3=tri-iodothyronine. $\mathrm{rT} 3=$ reverse T3. PPS=physical performance score. $\mathrm{ADL}=$ activities of daily living. LES=leg extensor strength. IGS=isometric grip strength. $\mathrm{BMD}=$ bone mineral density. $\mathrm{kp}=$ kilopond. $\mathrm{NM}=$ physical unit measure (maximum strength in newtons $x$ the distance of the dynamometer of the knee in $m$ ). Reproduced from van den Beld and colleagues, ${ }^{11}$ by permission of Oxford University Press. 

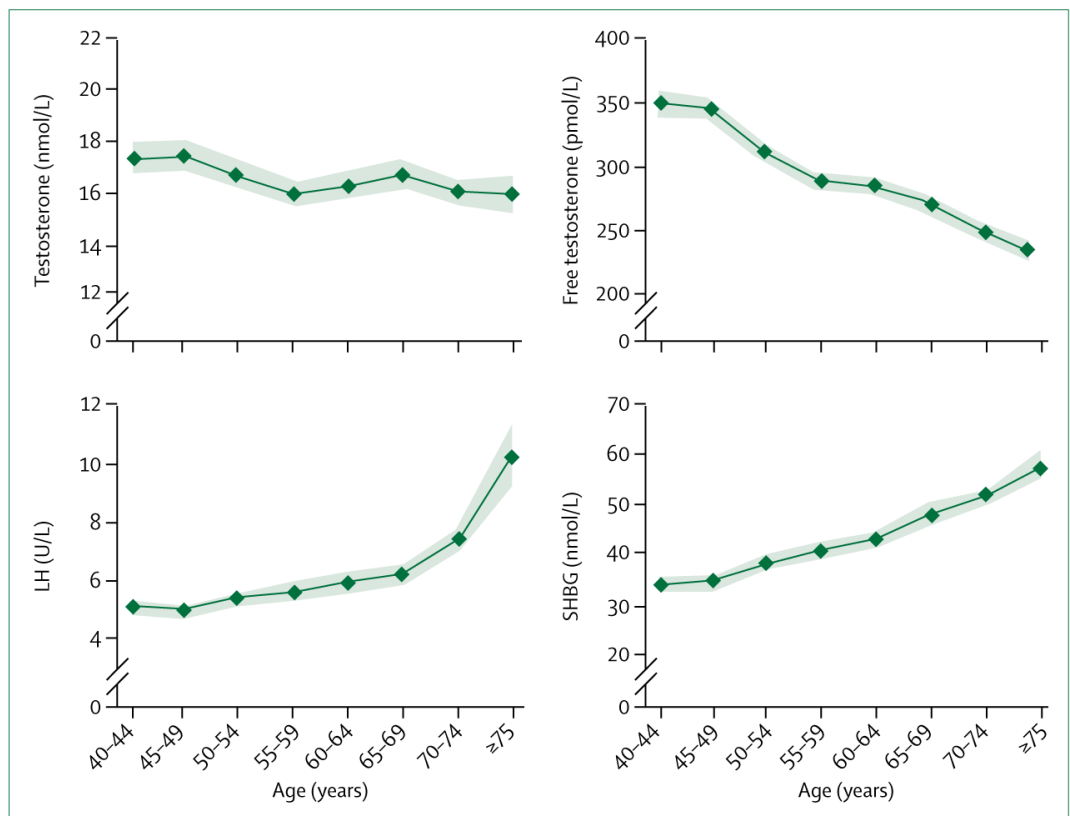

Figure 3: Relationship between age and hormones

Mean hormone concentrations (datapoints) with $95 \%$ CIs (shaded area) are presented in 5 year age bands for a cohort of 3220 men living in Europe. ${ }^{70}$ Mean hormone concentrations with increasing age were interpolated to approximate the age trend. Total testosterone and free testosterone were significantly lower ( $\mathrm{p}<0001)$, and the concentrations of LH and SHBG were significantly higher $(\mathrm{p}<0001)$ in the older age groups. The concentration of LH increased substantially at around age 70 years. Reproduced from $\mathrm{Wu}$ and colleagues,${ }^{70}$ by permission of Oxford University Press. LH=luteinising hormone. SHBG=sex hormonebinding globulin. 

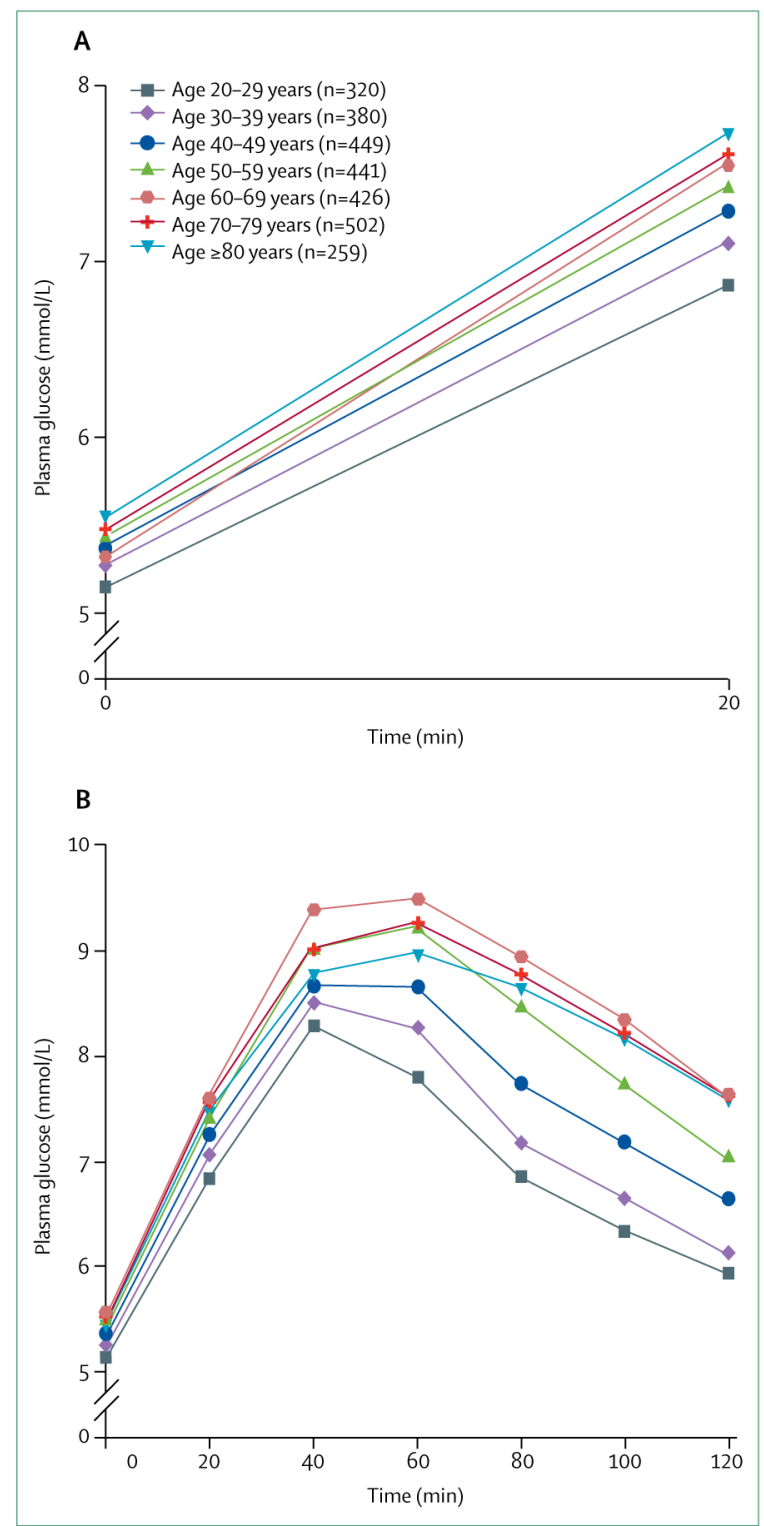

Figure 4: Concentrations of fasting plasma glucose and plasma glucose after oral glucose administration over time in non-diabetic individuals.

The concentrations of fasting plasma glucose (A) and plasma glucose (B) after the administration of $75 \mathrm{~g}$ oral glucose (oral glucose tolerance test) were measured over time in non-diabetic individuals. Data are means from the Baltimore Longitudinal Study of Aging (BLSA), from participants aged 20-89 years who were receiving no anti-hyperglycaemic medications. Oral glucose tolerance tests were done in all individuals at their first visit to the BLSA. The individuals presenting for their first visit were healthy with no known active disease, and were therefore not representative of the general population. Josephine M Egan, unpublished data. 